cysts. The establishment of a cavernostomy track followed by thoracoscopic removal of the cyst remnants provides a suitable alternative to thoracotomy, especially when the space is infected. Thoracoscopic removal of live or uncomplicated hydatid cysts does not afford the advantage of capitonage for control of bronchial air leaks and may lead to spillage and pleural recurrence, ${ }^{5}$ although we have not seen this, and so this procedure was not attempted for the cyst on the left side. It is anticipated that as expertise with and instrumentation for video-assisted thoracoscopic surgery continue to improve, such management may be preferred for live hydatid cysts as well.

\section{REFERENCES}

1. Le Roux BT. Pulmonary hydatid disease. Thorax 1972;27(3): 365-367.

2. Aytac A, Yurdakul Y, Ikizler C, et al. Pulmonary hydatid disease: report of 100 cases. Ann Thorac Surg 1977;23:145-51.

3. Dogan R, Yuksel M, Cetin G, et al. Surgical treatment of hydatid cysts of the lung: report on 1055 patients. Thorax 1989;44:192-9.

4. Aggarwal P, Wali JP. Albendazole in the treatment of pulmonary echinococcosis. Thorax 1991;46:599-600.

5. Barrett NR, Thomas D. Pulmonary hydatid disease. Br J Surg 1952;40:222-44.

\title{
VENTILATORY SUPPORT WITH A CUIRASS RESPIRATOR AFTER RESECTION OF BULLOUS EMPHYSEMA: REPORT OF A CASE
}

Koji Chihara, MD, ${ }^{\text {a }}$ Takao Ueno, MD, ${ }^{\text {a }}$ Shinichi Itoi, MD, ${ }^{\text {a }}$ Masanao Nakai, MD, ${ }^{\text {a }}$ Hisashi Sahara, MD, ${ }^{\text {a }}$ Susumu Oguri, MD, ${ }^{\mathrm{b}}$ Yoshihiro Ozawa, MD, ${ }^{\mathrm{b}}$ Shigeru Tanaka, MD, ${ }^{\mathrm{b}}$ and Takeo Hirata, MD, ${ }^{\mathrm{b}}$ Shizuoka, Japan

Positive-pressure ventilation (PPV) after operation for emphysema is undesirable because it often yields a persistent air leak. We report a case in which hypercarbia after bullectomy was treated successfully by negativepressure ventilation (NPV) with a cuirass respirator (Sumitomo Bakelite, Japan). ${ }^{1}$

Case report. In June 1995, an 82-year-old man with emphysema was transferred to our hospital for severe dyspnea and unconsciousness. Arterial blood gas measurements showed an oxygen tension of $74 \mathrm{~mm} \mathrm{Hg}$, a carbon dioxide tension $\left(\mathrm{PCO}_{2}\right)$ of $141 \mathrm{~mm} \mathrm{Hg}$, and the chest radiograph revealed left pneumothorax. An endotracheal tube and a chest tube were immediately inserted. The patient was extubated for 1 day after PPV. The computed tomographic scan revealed giant bullae in the left lower lobe (Fig. 1). Because air leakage had been intractable for a month, we performed a left thoracotomy. Air leakage from the bullae was $40 \%$ of inspired tidal volume. A $75 \mathrm{~mm}$ linear stapler covered by a sheath-shape fabric made from polyglycolic acid (Neoveil; Gunze, Japan) was used for bullectomy three times. Small air leaks at the stapling junctions needed

From the Departments of Thoracic Surgery ${ }^{\mathrm{a}}$ and Respirology, ${ }^{\mathrm{b}}$ Shizuoka City Hospital, Shizuoka, Japan.

Received for publication Oct. 3, 1995; accepted for publication Oct. 10, 1995.

J Thorac Cardiovasc Surg 1996;111:1281-3

Copyright (C) 1996 by Mosby-Year Book, Inc.

$0022-5223 / 96 \$ 5.00+0 \quad \mathbf{1 2 / 5 4} / \mathbf{6 9 7 5 8}$ additional sutures and fibrin glue. After the absence of air leaks was confirmed, the chest was closed. Although reversal of muscle relaxation was accomplished, tidal volume was less than $100 \mathrm{ml}$. Intermittent manual ventilation failed to decrease $\mathrm{PCO}_{2}$. Air leakage began in the meantime. We transferred the patient to the recovery room and started NPV with a cuirass respirator. ${ }^{1}$ An inspiratory peak pressure of $-30 \mathrm{~cm} \mathrm{H}_{2} \mathrm{O}$ at a rate of 20 breaths/min by the respirator had been applied for 4 hours. Tidal volume increased from 113 to $185 \mathrm{ml} . \mathrm{PCO}_{2}$ gradually decreased, and the patient became alert. He breathed spontaneously after NPV and was extubated thereafter (Fig. 2). The degree of air leakage did not change during NPV. The patient had been showing a slow but steady recovery; however, right pneumothorax suddenly occurred 3 weeks after operation. Because air leakage was again persistent, right thoracotomy was obligatory 3 weeks later. An air leak from a small bulla of the apex of the lower lobe was closed tightly. Because the patient had been feeling discomfort and vomiting after meals after operation, intravenous hyperalimentation was begun. Although the patient, once more made a slow recovery, he reported general malaise and productive coughs a week later, and $\mathrm{PCO}_{2}$ then was $86 \mathrm{~mm} \mathrm{Hg}$. We began PPV, but the patient died of heart failure 2 days later.

Discussion. The most troublesome complication after operation for emphysema is prolonged air leakage. Cooper and colleagues ${ }^{2}$ pointed out two important points in avoiding this complication. One is making every attempt to completely eliminate air leaks during operation. The other is avoiding excessive stress on the lung surface after operation. ${ }^{2}$ To accomplish the latter point, recovery of 


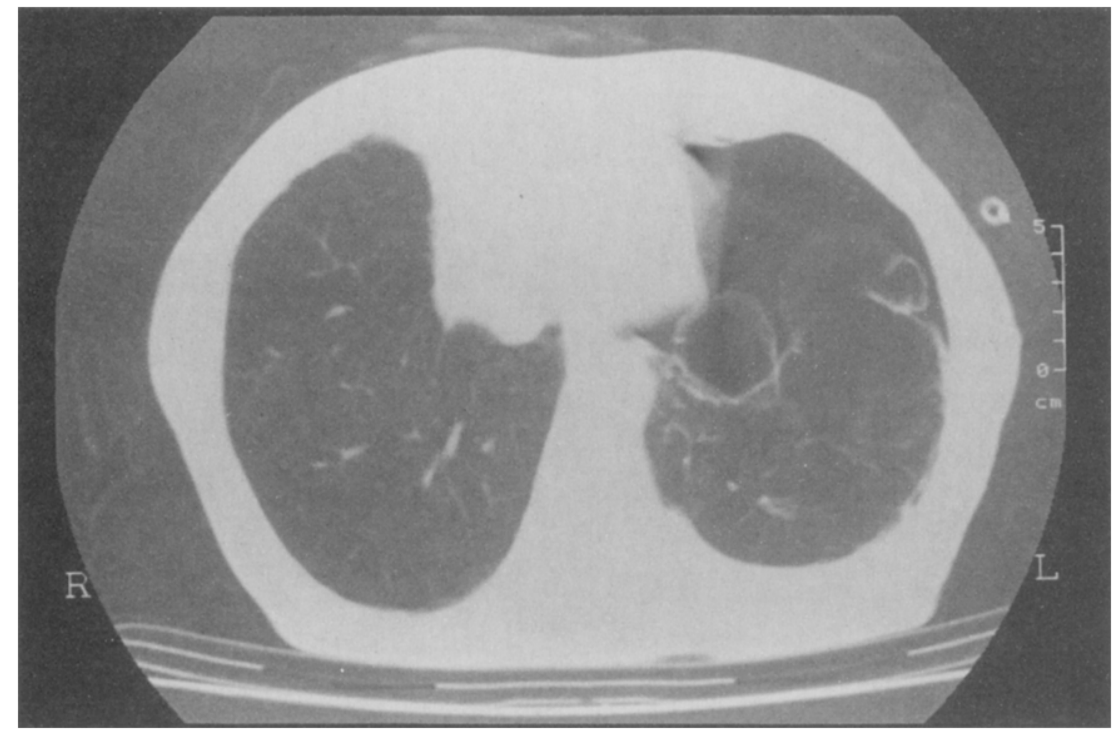

Fig. 1. Chest computed tomographic scan 2 weeks after admission shows giant bullae in the emphysematous lower left lobe.

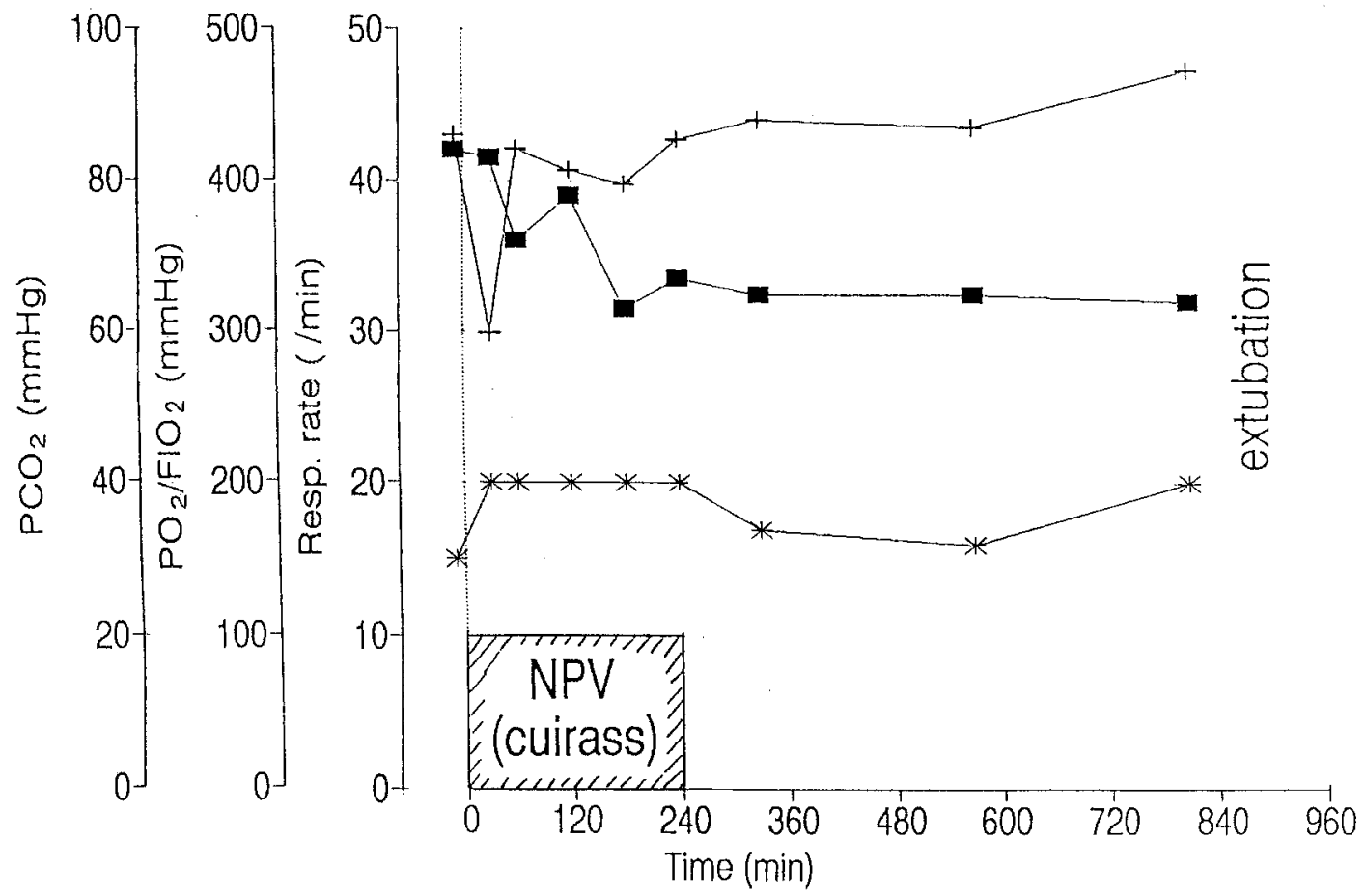

$\rightarrow-\mathrm{PCO} 2 \rightarrow \mathrm{PO}_{2} / \mathrm{FlO}_{2} \rightarrow$ Resp. rate $(\mathrm{min})$

Fig. 2. Arterial blood gas measurements and respiratory rate before, during, and after NPV.PO, Oxygen tension; $\mathrm{FiO}_{2}$, inspired oxygen fraction. 
spontaneous breathing as soon as possible ${ }^{2}$ and lowpressure suction of the chest tubes after operation are critical. ${ }^{2,3}$ Some ventilatory support is necessary, however, when a patient continues to have hypoventilation after operation. Pressure-controlled ventilation rather than volume-controlled ventilation has been recommended for such patients because it can deliver high inspired gas flows in the presence of airway leaks. ${ }^{3}$ Although NPV is generally less effective than PPV, ${ }^{1}$ it places less stress on the airway. Even if a peak inspiratory pressure inside the cuirass respirator is highly negative, a fraction of the pressure is transmitted to pleural pressure in patients with chronic obstructive pulmonary disease during cuirass ventilation. ${ }^{4}$ Marino and Pitchumoni ${ }^{4}$ showed that esophageal pressure decreased from $-5.4 \mathrm{~cm}$ $\mathrm{H}_{2} \mathrm{O}$ during spontaneous breathing to $-7.3 \mathrm{~cm} \mathrm{H} \mathrm{H}_{2} \mathrm{O}$ during inspiratory cycle of NPV while an inspiratory peak pressure of $-40 \mathrm{~cm} \mathrm{H}_{2} \mathrm{O}$ inside the cuirass worked on the chest. In contrast, during PPV a high positive peak pressure is transmitted to the airway and lung. NPV may therefore be less likely than PPV to induce barotrauma in patients with fragile stapling lines of the lung. Indeed, the decrease in $\mathrm{PCO}_{2}$ in our patient may have been rather slow compared with PPV; however, NPV successfully led him to stable spontaneous breathing without increasing air leakage. Although our patient died, we believe that NPV with the cuirass respirator could be an appropriate ventilatory support for the patient with hypercarbia after operation for emphysema when the lung is adequately inflated.

\section{REFERENCES}

1. Chihara K, Kawarasaki S, Hitomi S, Shimizu Y. A new cuirass respirator synchronizing with spontaneous respiration and its clinical application [Abstract]. Chest 1988;94:44S.

2. Cooper JD, Trulock EP, Triantafillou AN, et al. Bilateral pneumenectomy (volume reduction) for chronic obstructive pulmonary disease. J Thorac Cardiovasc Surg 1995;109:106-19.

3. Barker S, Clarke C, Trivedi N, Hyatt J, Fynes M, Roessler P. Anesthesia for thoracoscopic laser ablation of bullous emphysemia. Anesthesiology 1993;78:44-50.

4. Marino WD, Pitchumoni CS. Reversal of negative pressure ventilation-induced lower esophageal sphincter dysfunction with metoclopramide. Am J Gastroenterol 1992;87: 190-4.

\title{
MEDIASTINAL HISTOPLASMOSIS CAUSING MASSIVE HEMATEMESIS
}

\author{
Margarita T. Camacho, MD, ${ }^{a}$ Morris Edelman, MB, BCh, ${ }^{b}$ Alla Rozenblit, MD, ${ }^{c}$ John C. McKitrick, PhD, \\ Kenneth Pinsker, MD, ${ }^{\mathrm{d}}$ and Stanley C. Fell, MD, ${ }^{\mathrm{a}}$ Bronx, N.Y.
}

The granulomatous lymphadenitis that occasionally follows pulmonary infection with Histoplasma capsulatum (HC) may lead to the development of mediastinal granuloma or may progress to diffuse mediastinal fibrosis. In some cases, the superior vena cava, tracheobronchial tree, pulmonary vasculature, or the esophagus is compressed or entrapped, with resultant compromise in function. ${ }^{1}$ Recurrent massive hematemesis from an esophageal ulcer caused by $\mathrm{HC}$ mediastinal granuloma has not previously been reported.

A 27-year-old, previously healthy Ecuadorian man was admitted after an episode of hematemesis. Ten days before admission, he reported pleuritic chest pain,

From the Departments of Cardiothoracic Surgery, ${ }^{\text {a }}$ Pathology, Radiology, ${ }^{\mathrm{c}}$ and Medicine, ${ }^{\mathrm{d}}$ Montefiore Medical Center, Bronx, N.Y.

Received for publication Sept. 12, 1995; accepted for publication Sept. $19,1995$.

J Thorac Cardiovasc Surg 1996;111:1283-6

Copyright $(\mathbb{C} 1996$ by Mosby-Year Book, Inc.

$0022-5223 / 96 \$ 5.00+0 \quad \mathbf{1 2 / 5 4 / 6 9 3 3 9}$ cough, and fever, for which antibiotics were prescribed. Physical examination revealed a hemodynamically stable man with a hematocrit of $40 \%$. Results of chest radiography and routine laboratory studies were within normal limits, tuberculin test results were positive, and results of human immunodeficiency virus testing were subsequently reported as negative. Esophagogastroduodenoscopy revealed a $5 \mathrm{~mm}$ ulcer on the right anterolateral wall of the esophagus $30 \mathrm{~cm}$ from the incisors. The biopsy sample from the ulcer was described as granulation tissue with no growth on culture. The esophageal lumen was not narrowed, and the stomach and duodenum appeared unremarkable. Computed tomography of the chest demonstrated a $3 \times 4 \mathrm{~cm}$ subcarinal mass inseparable from the midthoracic esophagus and deformity of the medial wall of the bronchus intermedius (Fig. 1). During the ensuing 10 days during which further diagnostic studies were performed, the patient had four episodes of hematemesis, necessitating transfusions of 8 units of blood; on one occasion, the patient's hematocrit fell to $20 \%$. A barium esophogram was unremarkable. Flexible bronchoscopy revealed elevation and edema of the floor of the right 